\title{
THE EARLY DESCRIPTIONS OF AORTIC INCOMPETENCE
}

\author{
BY \\ RISTEÁRD MULCAHY \\ From the Cardiac Department, St. Vincent's Hospital, Dublin \\ Received November 23, 1961
}

In the preparation of an address on Sir Dominic John Corrigan (Mulcahy, 1961) it was necessary for me to read Corrigan's classical paper on permanent patency of the aortic valve (1832), and to attempt an analysis of the worth and originality of this famous monograph. This inevitably led me to the wider study of the history of aortic incompetence and to an appreciation of Flaxman's remark, noted in his paper on the history of this disease (Flaxman, 1939), that aortic incompetence was born and bred in controversy. The result of this study and of my recent investigations of earlier publications are now presented and it is hoped that some of the doubts that surround this interesting chapter in medical history will be resolved.

Calcific aortic stenosis was described by Riverius in 1646 and again by Bonet in 1679 (Willius and Dry, 1948). The first reference to aortic incompetence comes apparently from William Cowper the anatomist whose name is associated with the glands of the male urethra. He described clinical details of three cases and showed two pathological specimens to the Royal Society in 1705 . He had a clear appreciation of the effects of an aortic leak and noted the large left ventricle that he said was "larger than that of an ordinary ox."

Raymond Vieussens was professor of medicine at the University of Montpellier, physician to the Court of Louis Quatorze, and a man of immense energy, ambition, and curiosity. In his treatise on heart disease published in 1715, he gave the first accurate description of the pathology of mitral stenosis. In this same work he described the clinical course and pathological findings in a case of aortic incompetence in a man of 30: the pulse he described as full, hard, and strong, and he likened it to a violently shaken and tightly stretched cord striking the finger. From the character of the pulse and the patient's symptoms Vieussens had inferred the presence of heart disease.

J. B. Morgagni, professor of anatomy in the University of Padua, referred to aortic disease in 1761. He described the indurated and calcified aortic valve cusps found in a patient at autopsy and he considered that the valve was both stenotic and incompetent in its effects. In the same work he quoted a similar case described by Georgius Greiselius.

James Hodgson described two specimens of aortic valve involvement associated with dilatation of the aorta in his treatise on the disease of the arteries and veins published in London in 1815 and, about the same time, Dr. Baillie, in his morbid anatomy (quoted by T. Hodgkin, 1828-1829), referred to a specimen of the heart in Mr. Hunter's Museum with thickening of the aortic valve and partial rupture of a cusp.

These are the earliest descriptions of aortic disease. With the exception of Vieussens's clear account of the waterhammer pulse the authors were mainly concerned with pathological details.

It is necessary to consider at greater length Thomas Hodgkin's important contribution. He addressed the Hunterian Society of London in 1827 and again in 1829 on the subject, and his remarks were subsequently published in the London Medical Gazette under the title "On retroversion of the valves of the aorta" (Hodgkin, 1828-1829). Hodgkin's attention was first drawn to 
the disease by Mr. Aston Key, a surgeon. Amongst the case histories presented by him is that of a young colleague, a Dr. Cox, aged 30, who died from aortic incompetence. Hodgkin had noted the double murmur on auscultation and he stated that the carotids were seen to beat violently on both sides, thus anticipating by three years Corrigan's description of this sign. Hodgkin thus recognized some of the important signs of aortic incompetence although he was somewhat disorderly in his method of presentation and he was far from exact in explaining their genesis. He made a number of other points in diagnosis and treatment, but his very important contribution was almost obscured by Corrigan's later and more complete review. Subsequent efforts by medical historians such as Sir Samuel Wilks (1871) and Sir William Hale-White (1924) have gone some way to putting Hodgkin's name on the list of those who have contributed to the knowledge of aortic disease.

Another reference to aortic incompetence at this time was by Elliotson of St. Thomas' Hospital in the Lumleian Lecture of 1829. It was Elliotson who first used the term "permanent patency," a fact acknowledged by Corrigan. In 1831, Hope also described the pathology of the disease in some detail.

Corrigan's publication appeared in the Edinburgh Medical and Surgical Journal in 1832, when he was 30 years of age. He described the pathology of the disease fully and with care, including in his description the four important types of valvular anomaly, namely, cribriform or patchy defects in the cusps, rupture of a cusp, shortening and thickening of the valve leaflets, and, finally, gross dilatation of the aortic ring. These observations on the pathology of the disease were by far the most complete and accurate at the time.

He dwelt at length on the visible pulsation of the large vessels of the head and neck, and he properly attributed this increased pulsation to the large stroke output of the left ventricle followed by the retrograde flow during diastole. He noted the well-known effect of posture on the pulse and explained the genesis of this phenomenon. Corrigan only referred en passant to the palpable jerky pulse of aortic incompetence and mention has been made of the more dramatic and enduring description of this sign published by Vieussens in 1715. One should be careful therefore to use the term "Corrigan's pulse" only when one is referring to the visible pulse in the neck. The palpable pulse is the waterhammer pulse, or, alternatively, if one prefers an eponymous term, the pulse of Vieussens.

Corrigan then considered the bruit de soufflet, or bellows murmur, which he regarded as a pathognomonic sign of aortic incompetence always best heard at the base of the heart and going into the great vessels, sometimes as far as the elbow. This murmur, often accompanied by frémissement, or a palpable thrill in the vessels, is synchronous with the pulsation in the vessels and therefore systolic in timing. When the deficiency of the valves is considerable, he states, a double bruit is heard, but he referred only casually to this diastolic element and returned to the more serious discussion of the systolic bruit de soufflet. This surprising preoccupation with a systolic murmur, with or without a thrill, is most interesting, and I feel one is justified in speculating that many of Corrigan's patients may have had combined aortic stenosis and incompetence. No doubt the stethoscope of that day was far from efficient in detecting the high frequency, blowing diastolic murmur. Hence the reference to the double murmur only when the deficiency of the valve is considerable.

Corrigan went into detail about the causation of the bruit de soufflet and he quoted his experiments with a closed system of tubing to illustrate the connection between turbulence and the production of murmurs. This experimental work was first alluded to in a note to the Lancet (1828$1829,2)$. He was impressed by the size of the left ventricle noted at autopsy and stated that it resembled rather the heart of a bullock than that of a man. This is not the first reference to the cor bovinum as we know from reading William Cowper's earlier account. It is of clinical interest that he dwelt on the frequency of a poor apical impulse, despite this huge left ventricle, and one must assume therefore that many of his cases were in heart failure when first seen.

On the subject of diagnosis he mentioned the important difference between aortic incompetence and such conditions as mitral disease, aneurysm, and hyperkinetic states. Referring to aortic stenosis, he stated that the systolic murmur and powerful left ventricle are common to both, but that the small contracted pulse of stenosis contrasted with the full and swelling pulse of regurgitation. 
As regards ætiology, he recognized that aortic disease had a variety of causes including rheumatism, aneurysm, and trauma. He related prognosis to the size of the leak and he rightly considered that sudden death was not a feature in aortic incompetence and that the patient might therefore be reassured on this point.

On the subject of treatment he stated that "under proper restriction the patient is not only able to lead an active life for years, but is actually benefited by doing so." He attacked the whole principle of treatment by debilitating measures and differed from the conventional views of his contemporaries in this respect. He recognized ventricular hypertrophy as nature's attempt to endow the heart with added strength and he deplored any treatment calculated to interfere with this arrangement. He went on to refer to "the constant struggle between nature and medicine. The repeated bleedings, the starvings, the enforcement of debilitating measures are totally unsuited to the disease we are considering." Instead he recommends "good diet, abstinence from alcohol, normal activities and reassurance about sudden death."

It is clear that Corrigan's paper was by far the most thoughtful and comprehensive account then available. His description of the pathology and physical signs, although not entirely original, was up to then the most complete, and his experimental approach and physiological insight in these early years merit generous praise. Also this description was enhanced by his views on prognosis and his rational outlook on treatment.

Perhaps there is, in general, a wrong emphasis on the credit due to Corrigan. We think of his description of the physical signs of aortic incompetence instead of his broader contribution on the physiology and pathology, the diagnosis, prognosis, and treatment of this condition. He provided for the first time a synthesis of ideas and facts that formed a clear picture of the disease and was immediately and widely acknowledged. I believe many of his contemporaries were familiar with at least some of the clinical and pathological details of aortic disease at the time, for knowledge of heart disease was spreading as rapidly as the use of the stethoscope, but Corrigan apparently had the necessary energy, and the necessary experimental and clinical experience to lead the profession in his first really full account.

Following Corrigan's paper cases were freely described, but I cannot finish without referring again to James Hope, physician to St. George's Hospital and a man of exceptional energy and talent. He was clearly first in the field in describing the auscultatory signs of mitral incompetence and stenosis, and amongst many other contributions he noted the frequent association of pulmonary stenosis with atrial and ventricular septal defects. Hope had the reputation of being argumentative and contentious and he clashed with Corrigan on several occasions.

In 1830, in the Dublin Medical Transactions, Corrigan had published an important monograph of fifty-two pages describing his complete views on the physiology of heart action. This monograph was based on his own experimental work which had been carried out on reptiles and fish. It was surprising, in view of the important and authoritative paper on aortic incompetence which appeared only two years later, and in view of his extensive experimentation, that he considered the apex beat to be caused by atrial systole, the first sound to be caused by the blood rushing into the ventricles, and the second sound by the striking together of the walls of the ventricles. His views were strongly and justifiably criticized by James Hope in the London Medical Gazette later in 1830, and Corrigan was to admit some of his errors in his later paper on aortic incompetence.

From reading the 3rd edition of Hope's Treatise of the Diseases of the Heart and Great Vessels published in 1839, it is apparent that the author adopted an equally critical view of Corrigan's paper on aortic incompetence which he inferred contained little original material. Hope was less than just in this attitude. In this third edition he claimed precedence for describing the typical palpable pulse before Corrigan, although he admitted that he failed to associate the pulse with a leaking aortic valve at the time. Also he denied that Corrigan noted the characteristic palpable pulse although Corrigan wrote "in conjunction with this may be remarked the pulse which is invariably full." These are some of the squabbles one reads about, and, indeed, one is impressed on reading the early literature how free our predecessors were in argument and criticism. 
In speaking of Hope one must of course refer to his greatest contribution to the knowledge of aortic disease. In 1835 he carried out a series of ingenious experiments on stunned asses with the purpose of confirming the cause of the second heart sound. By introducing a dissecting hook into the pulmonary artery and aorta he interfered with closure of the semilunar valves. He not only succeeded in confirming that semilunar valve closure caused the second heart sound, but he also established that a leaking semilunar valve could be identified by a murmur commencing with or replacing the second heart sound. He was the first, therefore, to identify the early diastolic murmur as an important auscultatory sign of aortic incompetence: before this aortic incompetence and stenosis were to some extent confused. Indeed Hope referred to the early diastolic murmur as early as 1831 on page 340 of the first edition of his Treatise. Hope also noted the distribution of the early diastolic murmur along the left ventricular outflow tract and he referred to its musical quality.

Thomas Watson, physician to the Middlesex Hospital and lecturer in medicine at King's College, was the first person to use the analogy of the Victorian toy, the waterhammer, in describing the pulse. He was a close friend of James Hope, attended him during his last illness and was present at Hope's autopsy. Watson's description appeared in his Principles and Practice of Physick published in London in 1843.

Paul Duroziez of Paris described the double intermittent crural souffle in 1861 and Austin Flint, in a publication in the American Journal of Medical Science of 1862 , described a diastolic bruit heard in the mitral area in two patients subsequently proved to have isolated aortic incompetence. Flint's views on the cause of the mitral bruit led to much speculation and argument. Many fanciful ideas were put forward but the simple explanation of turbulence extending along the left ventricular outflow tract to the apex seems to have escaped the earlier workers.

I am grateful to Dr. Evan Bedford for assistance in the preparation of this paper.

\section{REFERENCES}

Corrigan, D. J. (1828-1829, 2). Inquiry into the causes of bruit de soufflet and fremissement cataire. Lancet, 2, $1-5$ and $33-35$.

(1830). On the motions and sounds of the heart. Dublin med. Trans., N.S.I., Pt. 1, 151-203.

(1832). Edin. med. surg. J., 37, 275.

Cowper, William (Abridged 1809), Trans. No. 299, p. 1970. Phil. Trans. Royal Soc. London, 5, 215-219, $1703-1712$. Quoted by Willius and Keys, Cardiac Classics.

Duroziez, P. (1861). Arch. gen. Med., 19, 417.

Elliotson, J. (1830). On the Recent Improvements in The Art Of Distinguishing The Various Diseases Of the Heart. Being The Lumleyan Lecture, 1829, London, Longman.

Flaxman, N. (1939). History of aortic incompetence. Bull. Hist. Med., 7, 192-209.

Flint, A. (1862). On cardiac murmurs. Amer. J. med. Sci., 44, 29.

Hale-White, W. (1924). Thomas Hodgkin. Guy's Hosp. Rep., 74, 117.

Hodgkin, T. (1828-1829). Retroversion of the valves of the aorta. London med. Gaz., 3, 433-443.

Hodgson, J. (1815). A Treatise on the Diseases of the Arteries and Veins. London, T. Underwood.

Hope, J. (1831). Treatise on the Diseases of the Heart and Great Vessels. 1st ed.

(1839). A Treatise of the Disease of the Heart. 3rd ed.

Morgagni, J. B. (1761). De Sedibus et Causis Morborum per Anatomen Indagatis, Libri Quinque, $23 . \quad$ (Trans. by Benjamin Alexander, London, 1869), 684.

Mulcahy, R. (1961). Sir Dominic John Corrigan. Ir. J. med. Sci., 430, 454.

Vieussens, R. (1715). Traité Nouveau de la Structure et des Causes du Mouvement naturel du Caur. Toulouse, J. Guillemete, 1715, 107.

Wilks, S. (1871). Note on the history of valvular disease of the heart. Guy's Hosp. Rep., $16,211$.

Willius, F. A., and Dry, T. J. (1948). A History of the Heart and Circulation. Philadelphia, W. B. Saunders Company, p. 456.

Those who are interested in the history of aortic incompetence will find the following additional monographs of value:

Dock, G. (1934). (1) Dominic John Corrigan: his place in the development of our knowledge of cardiac disease. (2) The waterhammer pulse. Ann. med. Hist., 6, 381-395.

Irvine, R. E. (1957). James Hope and the history of aortic regurgitation. Guy's Hosp. Rep., 106, 1-10.

Major, R. H. (1932). Raymond Vieussens and his treatise on the heart. Ann. med. Hist., 4, 147-154. 